\section{A Morte de José Fernando de Castro Figueiredo}

$\mathrm{N}$ a madrugada do dia 02 de dezembro de 2009, faleceu em uma das enfermarias do 10 andar do nosso Hospital das Clínicas (HC) da Faculdade de Medicina de Ribeirão Preto (FMRP-USP) o Prof. Dr. José Fernando de Castro Figueiredo, professor do Departamento de Clínica Médica desta Faculdade. Este foi o evento final de uma doença relativamente curta, que Ihe causou grande sofrimento e que trouxe enorme vazio para sua família e para as comunidades da FMRP-USP e do seu Hospital das Clínicas.

José Fernando foi uma pessoa ímpar, que conseguia combinar diferentes atributos, como permanente serenidade, discrição e modéstia, com características que Ihe eram muito próprias, como inteligência aguda e fino senso de humor. Conviver com ele era um prazer, que sua família, seus amigos mais chegados e seus colegas do Departamento, da FMRP e do HC dificilmente esquecerão.

Nascido na vizinha cidade de Altinópolis, José Fernando veio muito jovem para Ribeirão Preto para completar os seus estudos e realizar o seu sonho de se formar médico pela Faculdade de Medicina de Ribeirão Preto, que se concretizou em dezembro de 1974. Trouxe consigo o seu amor por Lenita, com quem se casou e sempre viveu em admirável harmonia. Com ela, teve as gêmeas, Eliza e Thaís, e, poucos anos depois, a caçula, Ana Maria. O casamento de Thaís com Orlando Ihe deu sua primeira neta, Helena, por quem tinha um carinho todo especial, que gostava de exibir, com graça, para os amigos da mesma faixa etária. Alguns anos depois, veio Francisco, que não chegou a conhecer, pois nasceu no dia 10 de dezem-

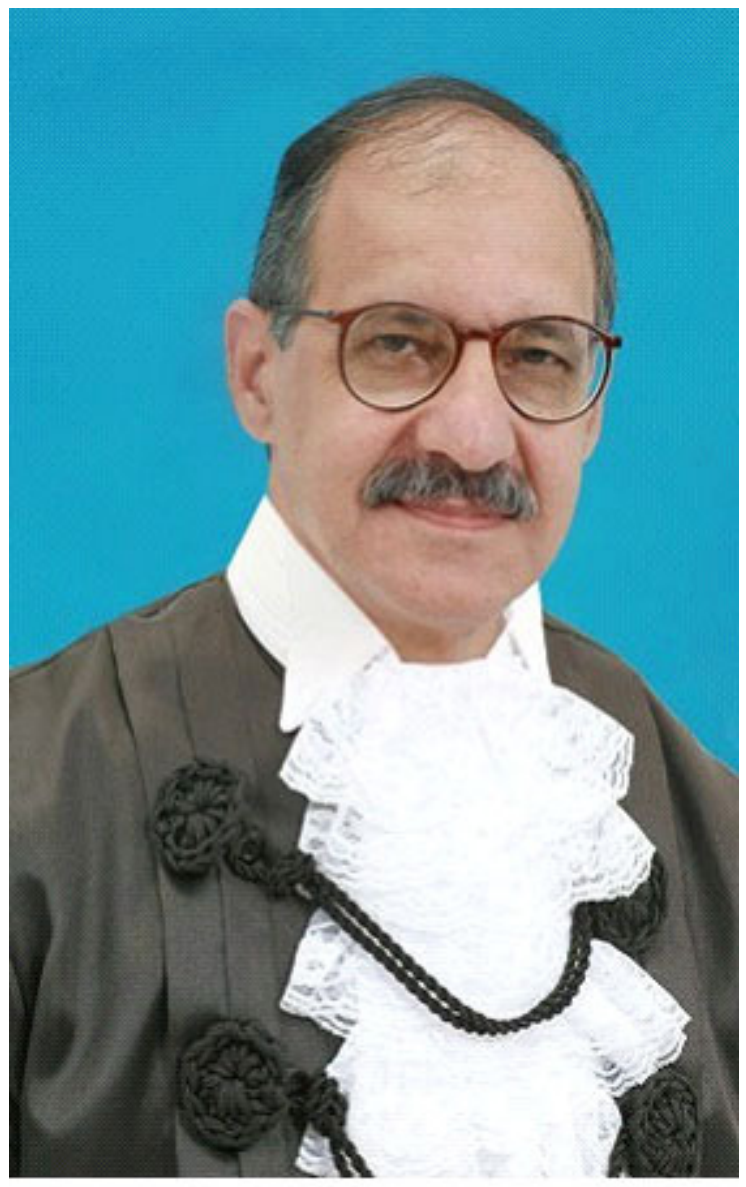

bro de 2009, no mesmo HC, poucas horas antes do falecimento de José Fernando. Nesta família, José Fernando era o centro, o apoio de todos e a referência para a solução dos problemas, como o foi para a sua família de origem, seu pai, sua madrasta, suas tias de Altinópolis, seu irmão e suas irmãs, seus cunhados e sobrinhos e, igualmente, para toda a família de Lenita.

Este papel peculiar que teve em família, era também sentido por aqueles que tiveram o privilégio de tê-lo como médico. Sempre atendeu com muita paciência os inúmeros colegas, amigos e vizinhos que a ele recorriam a qualquer hora, quando surpreendidos por condições agudas. Do mesmo modo, dedicava não só sua competência profissional, como também o seu afeto, aos muitos pacientes do HC, com condições clínicas que de- 
mandavam acompanhamento por muito tempo, que atendia pessoalmente nos ambulatórios ou na Clínica Civil.

Suas características pessoais Ihe propiciaram uma atuação singular em sua carreira docente na FMRP, por saber combinar com notável equilíbrio os papéis de professor, de médico e de investigador científico, conseguindo grande destaque profissional em cada uma destas vertentes. Apesar de receber evidências constantes de reconhecimento da excelência do seu trabalho nos campos do ensino, da pesquisa e da prática da Medicina, sua modéstia, aliada ao fato de lhe bastar a gratificação afetiva e intelectual que extraía do bom desempenho das suas tarefas do dia-a-dia, o levaram a optar por permanecer na posição de Professor Doutor do Departamento de Clínica Médica, jamais se inscrevendo para os concursos anuais para a obtenção do título de Livre Docente, que tinha todos os méritos para conseguir.

José Fernando era um professor admirável, especialmente em uma atividade docente que nos dias de hoje é exercida com precariedade, que é o ensino clínico "one-to-one", a beira do leito, que praticava com entusiasmo, seja com estudantes iniciantes, seja supervisionando sextanistas de Medicina e médicos residentes nas enfermarias de Moléstias Infecciosas e Parasitárias do HC, bem como nos plantões na Unidade de Emergência deste hospital. Suas qualidades de professor fizeram-no merecer inúmeras homenagens de turmas de formandos em Medicina da FMRP-USP, sua escolha como "Nome de Turma" da classe graduada em 1994, assim como sua indicação, por parte de estudantes e de docentes, conjuntamente, para receber o Prêmio UNIMED como professor de destaque no ensino de graduação da FMRP em 1993.

Como docente engajado, José Fernando não se limitou à prática, mas participou ativamente das instâncias administrativas responsáveis pela coordenação do ensino de graduação na FMRP, tanto no Departamento de Clínica Médica, como coordenador do internato médico e como preceptor dos médicos residentes, como no âmbito das instâncias centrais da FMRP-USP, como membro titular da Comissão de Graduação e como coordenador, por muitos anos, do Centro de Apoio Educacional e Psicológico (CAEP).

Como professor de formação acadêmica, José Fernando expandiu os horizontes da sua atuação, tendo um papel de realce em um grupo dedicado ao desenvolvimento e pesquisa em Educação Médica, que foi responsável por inovações na FMRP, como o projeto de avaliação terminal do graduando e a introdução do programa de tutoria ("mentoring") ao estudante de Medicina. Foi também responsável pela condução de investigações em diferentes campos, como o da avaliação do aprendizado do estudante, especialmente o das habilidades clínicas, o estudo dos fatores que determinam a escolha da especialidade médica e a caracterização da percepção do estudante sobre o papel do professor. Destes trabalhos resultaram diversos artigos que foram publicados em revistas nacionais e internacionais.

Como cientista e profissional da Infectologia, atuando na Divisão de Moléstias Infecciosas e Parasitárias do Departamento de Clínica Médica da FMRP-USP, José Fernando teve também atuação marcante em suas linhas de pesquisa mais relevantes, que incluíam os estudos clínicos, soroepidemiológicos e do tratamento das hepatites virais, o desenvolvimento de métodos de diagnóstico sorológico, o estudo de diferentes aspectos das infecções em pacientes imunossuprimidos, bem como a epidemiologia e o controle de infecções hospitalares. Atuando nestas linhas, desde seu tempo como estudante de pósgraduação no início dos anos 1980, participou da autoria de 116 artigos e 12 capítulos de livros, publicados no Brasil e no Exterior, além de 219 comunicações em eventos científicos. Teve, ainda, centenas de participações em bancas de concursos e de defesas de dissertações de mestrado e teses de doutorado em várias instituições do país. 
Uma característica da sua atuação científica, certamente determinada por sua área de atuação, mas também ditada por suas características pessoais, foi a abertura às colaborações com colegas de outras áreas, como a Gastroenterologia, a Nefrologia, a Hematologia, a Nutrologia, a Dermatologia, a Neuropsiquiatria, a Pediatria, a Epidemiologia e a Saúde Pública, a dos Transplantes, a Otorrinolaringologia e a Oftalmologia, entre outras. A qualidade deste trabalho é refletida pelos diversos prêmios das sociedades nacionais de Dermatologia e de Oftalmologia, que se somaram aos da área de Infectologia, que foram outorgados a trabalhos de pesquisa de que José Fernando participou.

Uma parte importante da sua atuação como docente foi a orientação dos estudantes e profissionais em formação, atividade que José Fernando exerceu sempre com grande dedicação, transferindo generosamente o seu conhecimento e, sobretudo, servindo como "role model". Beneficiaram-se desta atuação, diretamente, nove estudantes de iniciação científica, dezenas de médicos residentes, oito mestrandos e quatorze pós-graduandos em nível de doutorado, além de muitos outros que co-orientou ou auxiliou transitoriamente.
Na linha de trabalho de controle das infecções hospitalares, além da pesquisa científica, atuou por mais de 15 anos como Presidente da Comissão de Uso e Controle de Antimicrobianos (CUCA) do HC da FMRP-USP, desenvolvendo, com um grupo seleto de profissionais, um notável trabalho de educação de equipes e de prevenção das infecções hospitalares, que resultou em grande economia de recursos e, sobretudo, de vidas dos pacientes internados no HC da FMRP-USP e em outras instituições brasileiras que se espelharam no trabalho da CUCA local. Este é um breve resumo da vida e da obra de José Fernando de Castro Figueiredo, que fornece apenas uma pálida idéia de quem foi este destacado colega do Departamento de Clínica Médica. A exata dimensão do seu valor como pessoa e como profissional da Medicina e da docência universitária somente poderá ser aquilatada por aqueles que tiveram o privilégio de com ele conviver e está muito além do que as palavras podem expressar.

\section{Prof. Dr. LUIZ ERNESTO DE ALMEIDA TRONCON}

Chefe do Departamento de Clínica Médica da FMRP-USP 